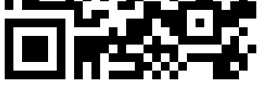

\title{
A política pública do Microempreendedor Individual como instrumento de precarização do trabalho feminino
}

Emanuele Mantovani, Universidade de Santa Cruz do Sul

A figura jurídica do Microempreendedor Individual foi criada em 2009 com o objetivo de reduzir a informalidade e a precarização do trabalho, além de garantir a inserção no mercado a trabalhadores desempregados. No entanto, por sua natureza, o trabalho como microempreendedor individual acaba representando uma forma de precarização das relações de trabalho, sobretudo para as mulheres. Este artigo tem o objetivo de analisar como a formalização como MEI, a partir da instituição desta política pública repercute na precarização do trabalho feminino. Para isso, foram aplicados formulários e foram feitas entrevistas semiestruturadas com mulheres que atuam como MEI para identificar de que forma a política pública se transforma em um mecanismo e ampliação da exploração do trabalho da mulher e das desigualdades que resultam da divisão sexual do trabalho.

Palavras-Chave: Empreendedorismo; Mercado de trabalho; Políticas públicas; Divisão sexual do trabalho. 


\section{Introdução'}

A Lei Complementar n. ${ }^{0} 128$ de 19 de dezembro de 2008, que cria a figura do Microempreendedor Individual é um desdobramento do Estatuto da Microempresa e Empresa de Pequeno Porte (Lei Complementar n. ${ }^{\circ}$ 123/2006, conhecida como Lei Geral da Micro e Pequena Empresa), criada em 2006 e que estabelece um tratamento diferenciado aos pequenos negócios. MEI é pessoa que trabalha por conta própria e que se "legaliza como pequeno empresário", necessitando, para isso, cumprir com determinadas exigências legais como faturamento máximo de $\mathrm{R} \$ 81$ mil por ano, não fazer parte de outra empresa como sócio ou proprietário e recolhimento de impostos e contribuições abrangidas pelo Simples Nacional em valores fixos nacionais. Ao mesmo tempo, o MEI torna-se portador de um conjunto de direitos: o registro no Cadastro Nacional de Pessoas Jurídicas; o enquadramento no Simples Nacional; a isenção de tributos federais e o pagamento de um imposto único; a inserção no Instituto Nacional de Seguridade Social (INSS). (BRASIL, 2008).

É importante notar que durante a década de 1990, no Brasil, os governos de orientação neoliberal, ainda que tenham conseguido conter a inflação, provocaram a desestruturação de importantes setores produtivos e, consequentemente, o desemprego e a vulnerabilidade das ocupações cresceram. Neste sentido, a figura do Microempreendedor Individual foi criada no Brasil como resultado de uma construção que envolveu organizações vinculadas a setores empresariais, movimentos sociais, sindicatos, universidades e governo a partir de preocupações que perpassavam desde o desenvolvimento de uma cultura empreendedora, melhores condições de trabalho, inserção de trabalhadores no mercado, garantias de proteção previdenciária, até a concepção de que não é possível alcançar a todos os trabalhadores com o assalariamento com carteira. Assim, a expectativa era de que a Lei pudesse contemplar uma estratégia de integração econômica e social a trabalhadores que estavam fora do mercado, ou inseridos em condições de precarização.

A criação desta política pública inscreve-se, portanto, em uma tentativa de integração de trabalhadores em situação de informalidade ou desemprego. Desde então, já foram mais de 7,5 milhões $^{2}$ de

$1 \mathrm{O}$ presente trabalho foi realizado com apoio da Coordenação de Aperfeiçoamento de Pessoal de Nível Superior - Brasil (CAPES) - Código de Financiamento o01.

${ }^{2}$ Em janeiro de 2021 o número total de MEIs chegou próximo a 10,8 milhões, sendo 5 milhões de mulheres e 5,8 milhões de homens. 
trabalhadores formalizados no Brasil, dos quais 3,5 milhões são mulheres, o que corresponde a 46,35\% do total de MEIs. Porém, é importante notar que a atividade profissional é vivenciada de formas diferentes por homens e mulheres: enquanto o homem tem no trabalho sua principal atividade a mulher tenta organizar sua carreira contemplando o equilíbrio entre a vida familiar e profissional, uma vez que na sociedade contemporânea, em muitos lares, ainda cabe à mulher a responsabilidade sobre as tarefas domésticas (BRASIL, 2019).

Assim, não raro, o trabalho da mulher é visto apenas como um complemento da renda da família. O trabalho por conta própria permite à mulher ter controle do seu tempo, porém, a vulnerabilidade do trabalho feminino na condição de empreendedora, contribui para manter a lógica patriarcal de subordinação da mulher. O sistema capitalista, ao mesmo tempo em que joga nos ombros da mulher o peso do trabalho na esfera produtiva, não a livra do trabalho na esfera reprodutiva para que, assim, o homem fique livre para se dedicar, exclusivamente, à produção de mais-valia. Esta é uma lógica que mantém toda a família em um sistema de exploração, mas, especificamente, a mulher (BRUSCHINI, 2007).

As dinâmicas da mão de obra feminina e da presença da mulher no mercado de trabalho são condicionadas por três fatores principais: a própria conjuntura do sistema capitalista e seus reflexos no mercado de trabalho com expansão ou retração das vagas, as mudanças nos processos e na organização do trabalho que, através da tecnologia aplicada na indústria, permitiram substituir o uso da força física por máquinas operadas por mulheres e, por fim, à subjetividade das trabalhadoras e sua vontade de entrar e se manter no mercado, uma vez que o trabalho passou a representar uma forma de autonomia e independência para as mulheres.

O processo de feminização do trabalho, ao mesmo tempo em que possibilita a entrada da mulher no mercado resulta em precarização da mão de obra e rebaixamento do padrão de uso da força de trabalho. Este movimento se inicia ainda na revolução industrial, quando o trabalho braçal pôde ser substituído por máquinas e possibilitou o ingresso de mulheres e crianças na indústria. Além disso, em nome da necessidade de conciliar trabalho e tarefas domésticas, do pressuposto de que tais tarefas são responsabilidade da mulher e de que o salário feminino é apenas um complemento à renda familiar há a legitimação de ocupações flexíveis para mulheres, que resulta em exploração. (NOGUEIRA, 2004) 


\section{A política pública do Microempreendedor Individual como instrumento de precarização do trabalho feminino}

Neste movimento contraditório, ao mesmo tempo em que o capitalismo cria condições para a emancipação da mulher ao inseri-la no processo de produção, através da ampliação da exploração, mantém a mulher em situação de subordinação. No Brasil, além da crise do assalariamento resultante da reestruturação produtiva da década de 1990, o incentivo ao empreendedorismo e a manutenção da concepção de que é da mulher a responsabilidade pela vida familiar, condicionam um grande número de mulheres ao empreendedorismo, seja em busca de emancipação, de um complemento para a renda da família ou de uma ocupação flexível que permita que ela continue responsável pelas atividades domésticas.

Segundo dados do relatório Global Entrepreneurship Monitor (GEM, 2017), enquanto que as mulheres são a maioria $(51,5 \%)$ nos novos empreendimentos (com até 42 meses), nos estabelecimentos com mais de 42 meses o número se inverte e os homens passam a ser maioria com $57,3 \%$. Isso mostra a dificuldade da mulher em se manter no mercado empreendedor. Os motivos desta inversão podem ser associados às dificuldades como entraves para conseguir financiamento, preconceito no ambiente de negócios e dificuldades em conciliar trabalho com as atribuições familiares.

Portanto, ainda que a presença da mulher no mercado de trabalho tenha aumentado e que quase metade dos registros como MEI sejam de mulheres, a ideia de que a mulher ainda é a principal responsável pelos cuidados (da casa, da família, dos filhos), a formalização como MEI pode se tornar um instrumento de precarização do trabalho feminino, na medida em que estas mulheres se inserem no mercado sem um trabalho protegido, sem direitos como férias e FGTS, ocupando postos temporários e de menor jornada. Assim, o objetivo deste trabalho é verificar em que medida esta política pública repercute em maior precarização do trabalho das mulheres (BRASIL, 2019).

Este estudo faz parte de uma dissertação de mestrado que analisou a construção social do microempreendedor individual em Santa Cruz do Sul. Os dados foram coletados entre janeiro e fevereiro de 2017 por meio de questionários e entrevistas semi-estruturadas. Os questionários foram respondidos por 45 mulheres e as entrevistas semiestruturadas por cinco. Além dessa seção introdutória, o artigo apresenta uma discussão sobre a reestruturação produtiva e a precarização do trabalho e uma seção que problematiza a divisão sexual do trabalho. No item a seguir são apresentados os dados sobre as mulheres 
microempreendedoras individuais em Santa Cruz do Sul e, por fim, as considerações finais.

\section{Reestruturação produtiva no Brasil e a precarização do trabalho}

A reestruturação produtiva no Brasil fez parte de um movimento global, na década de 1970, que marcou a passagem do sistema fordista para o pós-fordista, chamado por Harvey (2014) de "acumulação flexível”, que abriu espaço para novos setores e movimentou o emprego no setor de serviços, bem como de pequenas empresas familiares, muitas delas vinculadas a redes empresariais controladas por grandes empresas.

A partir dos anos 1980, em um contexto de renegociação das dívidas dos países da América Latina com os organismos internacionais como o Fundo Monetário Internacional e o Banco Mundial essa renegociação foi condicionada à adoção de políticas neoliberais por esses países. Essas medidas foram sistematizadas no "consenso de Washington", uma espécie de receituário neoliberal inspirado nos governos de Margareth Tatcher, na Inglaterra, e Ronald Reagan, nos Estados Unidos, na década de 1970. Entre as principais medidas propostas estavam o ajuste fiscal, a redefinição do tamanho e papel do Estado, privatizações, abertura comercial e o fim das restrições ao capital externo, abertura financeira, além da desregulamentação trabalhista e previdenciária (MANTOVANI, 2018).

Além da adoção do receituário neoliberal, a economia do Brasil na década de 1990 também foi marcada pelo controle inflacionário a partir da criação do Plano Real, junto com a abertura econômica que tinha como proposta inserir o país competitivamente no mercado global. Com a redefinição do papel do estado, a valorização da moeda, com o Plano Real, e uma elevada taxa de juros, as empresas exportadoras tiveram uma queda significativa na demanda. Foi neste contexto que ganhou força o discurso que defendia a desregulamentação do mercado de trabalho e a necessidade da flexibilização das relações trabalhistas. Assim, muitas empresas passaram para empresas menores, terceirizados ou autônomos a parte menos rentável da produção, com o objetivo de reduzir os custos (MANTOVANI, 2018).

A estagnação econômica da década de 1990, o desemprego gerado pelo desaquecimento da demanda e pela reestruturação 


\section{A política pública do Microempreendedor Individual como instrumento de precarização do trabalho feminino}

produtiva, somada à incapacidade de geração de novos empregos repercutiu no avanço das ocupações precárias, atirando parcelas significativas de trabalhadores para a informalidade. Assim, a redução dos postos de trabalho modificou não só o número de vagas, mas também a qualidade da ocupação gerada. Aquele período ficou marcado por um crescente número de vagas assalariadas sem registro e ocupações não assalariadas, sobretudo em micro e pequenas empresas familiares, implicando aumento considerável da precarização das condições de trabalho, situação que persistia ainda nos anos 2000. A título de ilustração, conforme a Pesquisa da Economia Informal do IBGE para o ano de 2003, atuavam no mercado informal, 10,3 milhões de trabalhadores, sendo 9,1 milhões ocupados por conta própria e 1,2 milhão como empregadores (POCHMANN, 2001).

Com a deterioração do trabalho assalariado, projetou-se a imagem de um trabalhador que substitui o emprego assalariado pelo trabalho individual, como "empresário de si mesmo". O fenômeno do autoemprego no Brasil ganhou força, sobretudo nos anos 1990, como expressão da reestruturação produtiva e do crescente número de desempregados. Empurrados pela falta de oportunidades no mercado formal de trabalho, um grande número de trabalhadores assumiu a modalidade de desemprego disfarçado, através do "empreendedorismo", num contexto de adaptação ao risco e à insegurança. (SILVA, 2002).

Para reverter a crise do emprego no Brasil, entre as demandas por políticas públicas para a ampliação da oferta de empregos, os principais aspectos se referiam à desburocratização das micro e pequenas empresas, à redução da carga tributária e ao estímulo ao associativismo. Essas e outras regulamentações formaram o conjunto normativo denominado Estatuto da Micro Empresa e Empresa de Pequeno Porte (Lei Complementar n. ${ }^{\circ}$ 123/2006, também conhecida como Lei Geral da Micro e Pequena Empresa), que estabeleceu tratamento diferenciado aos pequenos negócios. (COLBARI, 2007).

Também foi a Lei Geral que instituiu o Microempreendedor Individual, até então destituído de existência, estabelecendo um regime regulatório específico para o autoemprego. Para se enquadrar neste regime, há uma série de requisitos que devem ser atendidos como faturamento anual de, no máximo, $\mathrm{R} \$ 81.000,00$ por ano, não fazer parte de outra empresa como sócio ou proprietário e o pagamento do imposto único de valor fixo. Pode se formalizar como empreendedor individual o trabalhador assalariado e o empresário individual. Entre os 
principais direitos verificados com a formalização estão: - o registro no Cadastro Nacional de Pessoa Jurídica (CNPJ), que permite a emissão de nota fiscal e a participação em licitações; - o enquadramento no Simples Nacional; - o pagamento de um imposto único que corresponde à soma da contribuição previdenciária do empreendedor com o Imposto sobre Circulação de Mercadorias e Serviços (ICMS) ou o Imposto Sobre Serviços (ISS); - a contratação de até um funcionário; - a inserção no Instituto Nacional de Seguridade Social (INSS), por meio do qual fica garantido o auxílio maternidade, o auxílio doença e a aposentadoria. (BRASIL, 2008).

No entanto é importante considerar que, ainda que tenha sido criada com o objetivo de tirar da informalidade cerca de 4 milhões de trabalhadores que atuavam nesta condição, a política pública do Microempreendedor Individual em passível de se converter em um mecanismo de precarização do trabalho, uma vez que a reestruturação produtiva repercute em novas formas de organização e gestão da atividade laboral, sobretudo por meio da flexibilização do emprego e dos direitos trabalhistas. Essas práticas assumem diferentes características como a terceirização da mão de obra, o trabalho temporário, a subcontratação e a informalidade.

Neste sentido, a informalidade é representada pela fragilização dos vínculos formais de trabalho, onde o vínculo formal é substituído pelo trabalho autônomo ou sem carteira assinada. Os trabalhadores convivem com uma situação de instabilidade e perdem direitos como o FGTS, as férias, o seguro desemprego e a contribuição previdenciária. A informalidade ainda se manifesta em outras formas de organização como o trabalho autônomo, o autoemprego, o trabalho doméstico, em pequenos negócios familiares que prestam serviços para empresas maiores, cooperativas de trabalhadores e a subcontratação por meio de empresas de terceirização de mão de obra. (NASCIMENTO, 2014). Ou seja, o trabalho informal está relacionado a todas as formas de autoemprego, como uma estratégia de sobrevivência, que pode ser tanto no trabalho à domicílio, ambulante ou mesmo dentro de empresas formais, ou seja, rompendo com a lógica do trabalho assalariado padrão.

No que se refere à terceirização de trabalhadores, os aspectos mais relevantes a serem considerados são os contratos por tarefas específicas, as contratações em tempo parcial e o trabalho intermitente. Isso repercute, além da falta de proteção social e direitos trabalhistas, em insegurança, menor renda e renda flexível (que varia de acordo com a 


\section{A política pública do Microempreendedor Individual como instrumento de precarização do trabalho feminino}

demanda de trabalho), além do enfraquecimento dos laços de classe entre os trabalhadores e redução na capacidade de mobilização e organização sindical (ANTUNES, 2010). Esta modalidade de trabalho atípico é um fenômeno que envolve trabalhadores mais ou menos qualificados, com alta ou baixa remuneração, mas sobretudo as mulheres, em razão da divisão sexual do trabalho que insere as mulheres no mercado em uma condição desigual em relação aos homens.

\section{Divisão sexual do trabalho e precarização do trabalho feminino}

O processo de reestruturação produtiva no Brasil, na década de 1990, resultado dos governos de orientação neoliberal, repercutiu não só na emergência de um novo padrão de acumulação, mas também uma reorientação no mercado, nas relações sociais, na reconfiguração do mundo do trabalho na ressignificação da própria classe trabalhadora.

A crise do assalariamento combinada com incentivo ao empreendedorismo impulsionou o trabalho precário, terceirizado, informal ou em tempo parcial. Neste sentido, ganham importância as políticas públicas que contribuam com a desburocratização das empresas e com o aumento na formalização com o objetivo de proporcionar inclusão social e produtiva. É neste contexto que é criada a Lei do Microempreendedor Individual, que permite a formalização de negócios informais, a inclusão de trabalhadores no sistema previdenciário e a geração de trabalho e renda.

Em que pese o aumento da participação da mulher no mercado de trabalho desde a metade dos anos 1970 é importante notar que a inserção feminina no mercado sempre foi marcada pela vulnerabilidade. Permanecem as desigualdades de salário e condições de trabalho em relação aos homens, ao mesmo tempo em que não há uma reconfiguração na divisão do trabalho doméstico resultando em sobrecarga. Também é importante destacar a polaridade que marca o trabalho feminino, dividido entre mulheres com baixa escolaridade, que se dividem entre a atividade profissional e o trabalho doméstico e mulheres qualificadas que ocupam postos de trabalho de chefia e terceirizam para outras mulheres (empregadas domésticas e babás) os cuidados com a casa e a família. (BRUSCHINI e LOMBARDI, 2000) 
A feminização do trabalho e a participação cada vez maior da mulher no mercado não foram suficientes para romper com a ideia que atribui à ela a responsabilidade pelo lar e pelos filhos, da mesma forma que persiste a ideia de que o rendimento da mulher é apenas um complemento para a renda da família, que tem no homem o principal provedor. Estes são alguns dos fatores que impedem uma melhora nas condições de trabalho e rendimento das mulheres e faz com que alguns padrões de uso da força de trabalho feminino se mantenham. As desigualdades de salário não diminuem e as condições de trabalho não melhoram (BRUSCHINI, 2007).

É importante notar que a intensificação da presença da mão de obra feminina no mercado de trabalho é parte de um processo amplo de transformação do capitalismo, que é funcional ao aumento da acumulação de capital. Conforme Engels (1985) a Revolução Industrial, ao incorporar a força de trabalho feminina desvalorizou a força de trabalho de toda a classe trabalhadora. A utilização da tecnologia na indústria transformou o trabalho do homem adulto em supervisão, que passou a ser feita por mulheres e crianças "por metade ou mesmo um terço dos salários", rebaixando o padrão de remuneração da força de trabalho que, conforme o autor, já era baixo. (ENGELS, 1985, p. 190)

Isso mostra que a inserção da mulher no mercado de trabalho se deu em um contexto de desvalorização da mão de obra assalariada. Porém, de forma contraditória, se por um lado a presença feminina no mundo do trabalho permitiu à mulher dar um passo importante em seu processo de emancipação, a ocupação em postos mau remunerados e com rendimentos mais baixos que os dos homens apontam para a manutenção da desigualdade entre homens e mulheres e das relações de subordinação (NOGUEIRA, 2004). Um exemplo disso, são os dados da Pesquisa Nacional por Amostra de Domicílios (PNAD) de 2018, que indica que a quase totalidade $(92,6 \%)$ da população brasileira feminina de 14 anos ou mais, (mais de 80 milhões de mulheres), realiza afazeres domésticos e de cuidados, em uma média de 21 horas semanais, enquanto que os homens ocupam, em média, 10,8 horas semanais nessas tarefas (IBGE, 2019).

Essa divisão desigual das tarefas domésticas implica, também, em uma inserção desigual das mulheres no mercado de trabalho porque a dupla jornada é considerada um impedimento ao aumento da participação feminina na força de trabalho. Conforme os dados da PNAD, em 2018 a taxa de participação das mulheres ainda era quase 


\section{A política pública do Microempreendedor Individual como instrumento de precarização do trabalho feminino}

$20 \%$ inferior à dos homens $\left(52,7 \%\right.$ no $4^{\circ}$ trimestre de 2018 contra $71,5 \%$ deles) (IBGE, 2019).

Outro dado que sugere uma maior precarização da mulher no mercado de trabalho é no que se refere à jornada: em geral, as mulheres ocupam as vagas de menor jornada, assim como também são a maioria nas ocupações em tempo parcial, assim como em trabalhos temporários ou sazonais. Esta situação, além de reforçar o lugar de subordinação da mulher nas relações familiares, é funcional ao capital que também se vale do trabalho feminino na esfera reprodutiva (NOGUEIRA, 2004).

Ao abordar a divisão sexual do trabalho no contexto da reestruturação produtiva, Hirata (2005) observa duas tendências: em primeiro lugar, a bipolarização do trabalho feminino que segrega mulheres que ocupam profissões de nível superior e mulheres que ocupam postos na área de prestação de serviços; em segundo lugar, o desenvolvimento do setor de serviços, no caso feminino, sobretudo em ocupações na área de serviços pessoais, saúde e educação, movimento relacionado à crise econômica e à recessão que empurram as mulheres para setores de prestação de serviços, muitas vezes, de forma autônoma ou informal.

O aumento no emprego feminino no contexto da reestruturação produtiva na década de 1990 no Brasil foi acompanhado pelo aumento do trabalho precário e desprotegido caracterizado por ausência de proteção social e direitos sociais como previdência e o direito à sindicalização; horas reduzidas trabalho ou trabalho em tempo parcial que reflete na redução da remuneração; e, por fim, a baixa qualificação formal. (HIRATA, 2009)

Parte desta dinâmica é explicada por uma construção baseada no princípio da separação entre trabalho de homem e de mulher e, ainda mais significativo, no princípio de hierarquização que atribui uma importância maior ao trabalho do homem do que da mulher. Tendo o trabalho produtivo da mulher menor valor que o do homem, o trabalho reprodutivo é visto como uma extensão da jornada feminina ou um apêndice do trabalho assalariado. (KERGOAT, 2010)

Neste sentido, Kergoat, (2009) considera que as relações sociais de gênero e a divisão sexual do trabalho são indissociáveis e formam um sistema caracterizado pela relação antagônica entre os grupos, resultado de uma construção social, e não de um destino biológico. Esta relação de poder e dominação só poderá ser reconstruída de forma conectada com a 
divisão sexual do trabalho. Essas relações se apoiam em instituições que legitimam essa organização do trabalho e da família e as relações de força como questões naturais. (KERGOAT, 2009)

Esta concepção alimenta o paradoxo que, ao mesmo tempo em que a presença da mulher no mercado de trabalho aumenta, permanecem as desigualdades de salário e oportunidades, além disso, a mulher continua a assumir o trabalho doméstico, o que libera o homem para se dedicar com exclusividade ao trabalho produtivo. Sob esta perspectiva, tanto a divisão de tarefas, quanto a divisão sexual do trabalho entre homens e mulheres está associada a uma trajetória de subordinação que estabelece uma relação hierárquica entre os sexos.

\section{Microempreendedorismo feminino em Santa Cruz do Sul}

O município de Santa Cruz do Sul destaca-se territorialmente na região do Vale do Rio Pardo por sua importância econômica e por ser um polo de desenvolvimento regional. O município concentra as principais atividades industriais da região, além de um diversificado setor de comércio e de prestação de serviços. Foi a partir da instalação do complexo fumageiro transnacional e do processo de intensificação da industrialização que, entre os anos de 1960 e 1980, Santa Cruz do Sul chegou à posição de destaque no Vale do Rio Pardo e se tornou o principal município da região na oferta de estabelecimentos de serviços, educação, saúde e lazer (MANTOVANI, 2018).

As empresas beneficiadoras de tabaco influenciam diretamente nas dinâmicas do mercado de trabalho de Santa Cruz do Sul, pois, em função da sazonalidade na organização da produção do tabaco, nos primeiros semestres do ano o número de pessoas empregadas é maior do que o número de pessoas demitidas; em contrapartida, no segundo semestre o número de pessoas demitidas é maior do que o número de pessoas empregadas. Essa sazonalidade é resultado da dinâmica de produção da indústria fumageira que tem seu ápice nos primeiros semestres do ano, quando recebe o tabaco para o beneficiamento (MANTOVANI, 2018).

Assim, a safra do tabaco repercute na inserção dos trabalhadores que atuam de forma temporária e que por um período do ano ficam sem trabalho. Alguns dos safristas permanecem este período de tempo em 
casa, na espera do retorno para a indústria; outros buscam ocupações temporárias e informais e, dentre as opções de ocupação, alguns desempenham atividades como microempreendedor individual.

Para compreender as dinâmicas do mercado de trabalho de Santa Cruz do Sul no que se refere à atuação de mulheres na condição de microempreendedoras individuais, nesta seção serão apresentados os dados coletados nos formulários aplicados a 45 mulheres nos meses de janeiro e fevereiro de 2017 e nas entrevistas semi-estruturadas realizadas em maio do mesmo ano com cinco mulheres. Para contribuir com a análise, primeiro apresentam-se alguns dados em relação ao perfil socioeconômico das mulheres que atuam na condição de MEI em Santa Cruz do Sul.

Primeiro é importante atentar que, no período da coleta dos dados, Santa Cruz do Sul tinha 4.534 trabalhadores atuando como MEI, sendo 2.086 mulheres, o que representava cerca de $46 \%$ do total. No que se refere à idade (GRÁFICO 01), 33,33\% tem entre 30 e 39 anos, seguido pelo grupo com idades entre 40 e 49 anos (20\%), o que indica que a maioria dessas mulheres, de modo geral, já tem uma experiência acumulada no mercado de trabalho. As idades que variam entre 22 e 29 anos são as que menos têm mulheres atuando, o que pode indicar que a atividade como MEI não é a primeira opção de ocupação para as jovens que ingressam no mercado de trabalho.

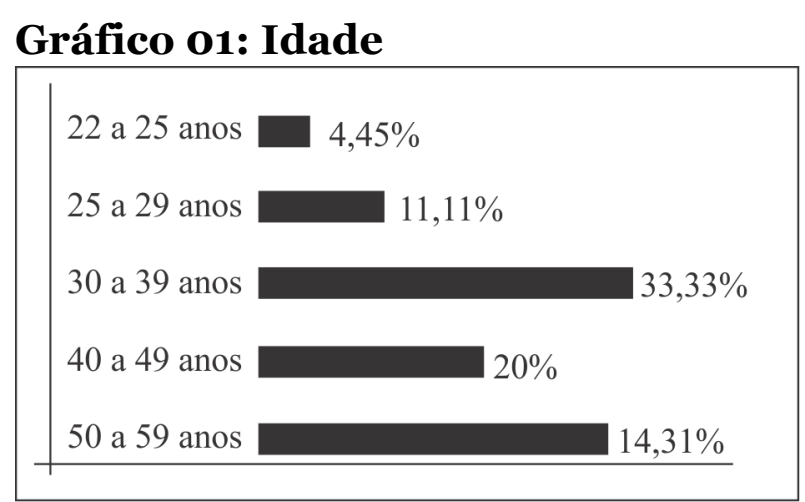

\section{Fonte: elaborado pela autora.}

No que se refere à escolaridade, $37,77 \%$ tem ensino médio completo (GRÁFICO 02), seguido pelo grupo com superior incompleto e superior completo. Os dados indicam que as MEIs têm escolaridade relativamente alta, principalmente se for considerado que quase $40 \%$ estavam cursando ou já haviam concluído o ensino superior. Os dados mostram que, se por um lado, há certa facilidade em cursar uma 
universidade (e neste sentido é importante destacar que Santa Cruz do Sul, tem uma universidade, uma faculdade presencial e vários pólos de instituições que oferecem formação à distância), por outro, a vulnerabilidade do mercado de trabalho atinge, inclusive, trabalhadoras com este nível de formação.

\section{Gráfico o2: escolaridade}

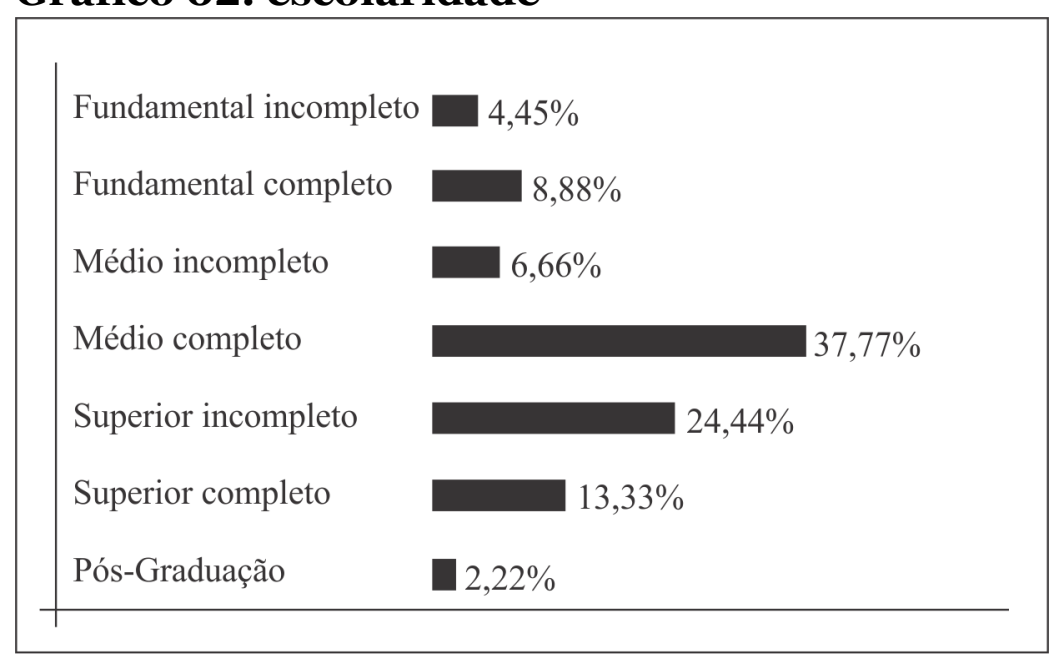

Fonte: elaborado pela autora.

A maioria das mulheres entrevistadas tem na atividade como MEI sua única fonte de renda, 64,44\% (GRÁFICO 03). As demais, além da atividade como MEI tem outra fonte de renda como emprego, aposentadoria ou "bicos" e trabalhos sazonais como cuidadora, babá, doméstica ou mesmo, renda proveniente de benefícios como pensão ou Bolsa-Família.

\section{Gráfico o3: Principal fonte de renda}

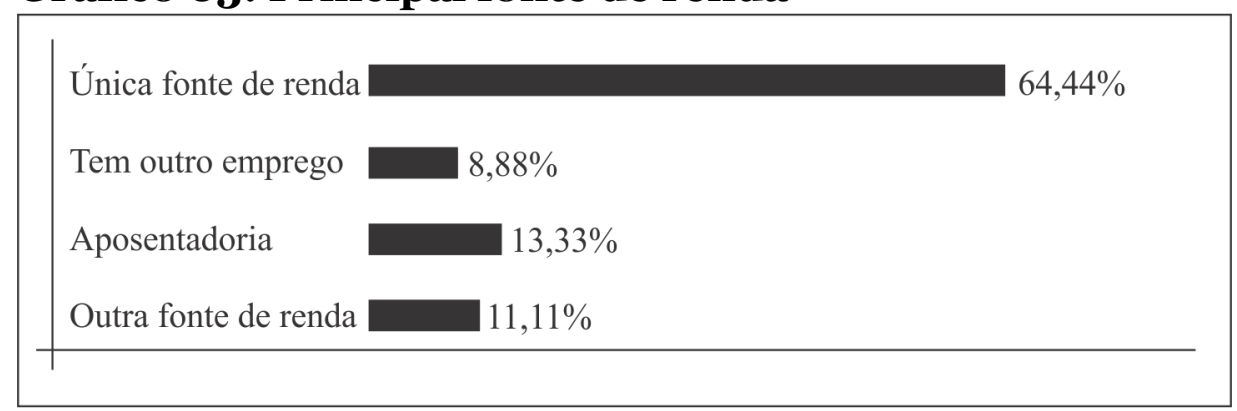

Fonte: elaborado pela autora.

Ainda no que se refere à renda, $42,22 \%$ das entrevistadas indicaram renda familiar média variando entre três e cinco salários mínimos (GRÁFICO 04), o equivalente a $\mathrm{R} \$ 2.800$,oo até $\mathrm{R} \$ 4.685$,00, seguido pelo grupo que indica renda familiar variando entre apenas dois 
e três salários mínimos. Ou seja, apesar de escolarizadas (a maioria com ensino médio, cursando ou com ensino superior concluído) a escolaridade das mulheres que atuam na condição de MEI não tem um reflexo significativo na renda familiar. Também chama a atenção que $4,44 \%$ das respondentes não sabem qual é o valor da renda de sua família.

\section{Gráfico o4: Total da renda familiar}

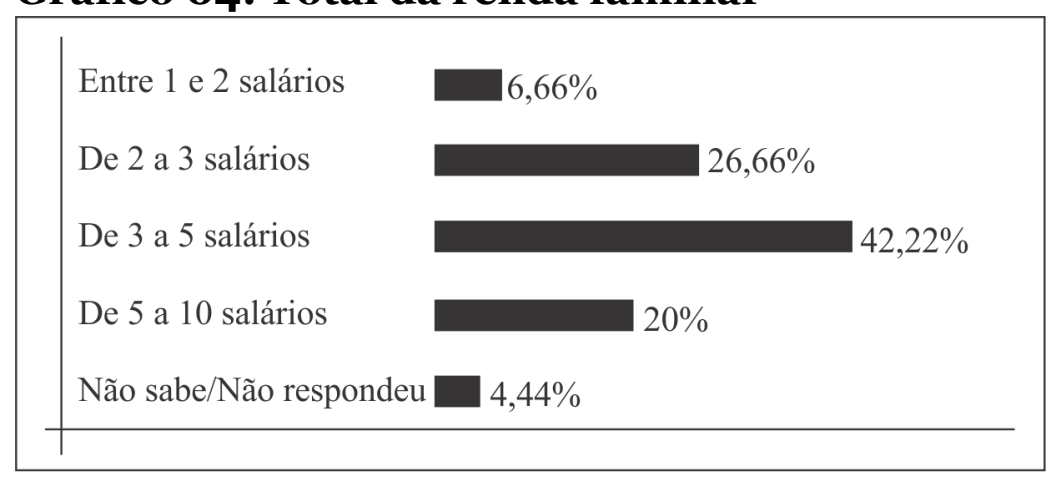

Fonte: elaborado pela autora

Outro dado em relação à renda, que vale ser destacado é que $46,66 \%$ das mulheres que atuam como MEI contribuem com valores entre $40 \%$ e $60 \%$ da renda familiar (GRÁFICO 05) e mais de $24 \%$ delas contribuem de $60 \%$ até mais de $80 \%$, o que demonstra a importância da renda obtida como MEI para a manutenção das famílias de uma parcela significativa das trabalhadoras.

\section{Gráfico o5: Porcentagem da renda em relação à renda da família}

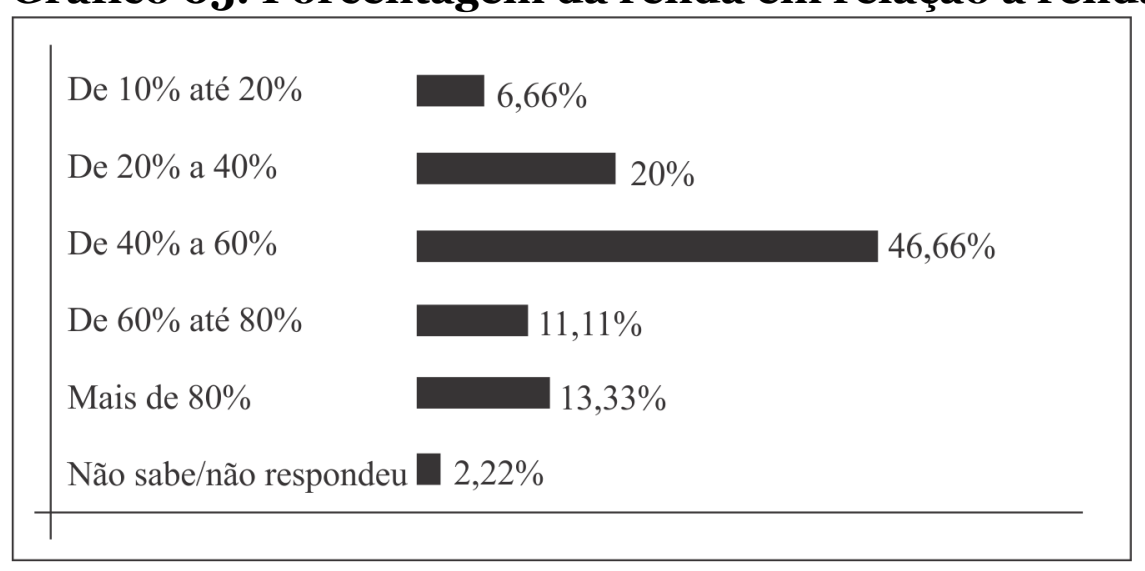

Fonte: elaborado pela autora.

No que se refere às atividades desempenhadas antes da formalização como MEI (GRÁFICO 06), mais da metade das entrevistadas $(55,55 \%)$ estavam empregadas com carteira assinada, o 
que demonstra que, em muitos casos, o que há é a substituição do trabalho protegido pela atividade como MEI. Também é importante destacar que mais de $33 \%$ das entrevistadas apresentavam algum nível de vulnerabilidade, seja atuando como empregada sem carteira assinada ou em negócios informais.

\section{Gráfico o6: Atividade profissional antes da formalização}

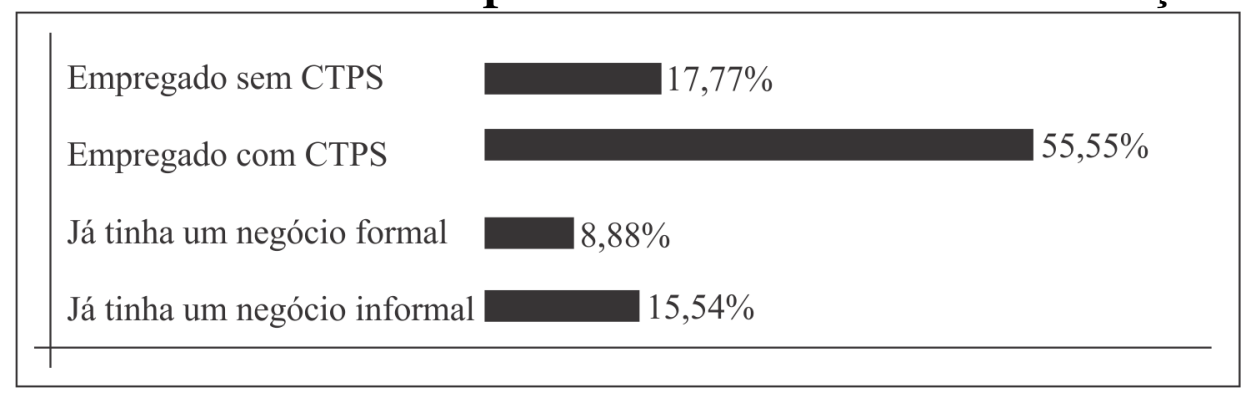

\section{Fonte: elaborado pela autora}

Quanto ao motivo do registro como MEI, 48,88\% referem como principal motivo a formalização das atividades econômicas (GRÁFICO 07). No entanto, é importante registrar que, mesmo para as trabalhadoras que referiram como principal motivo ter uma empresa formal, o desejo de formalização passa, diretamente, pelo desejo de segurança, acesso a direitos, benefícios previdenciários e oportunidades.

\section{Gráfico o7: Motivo pelo qual se formalizou como MEI}

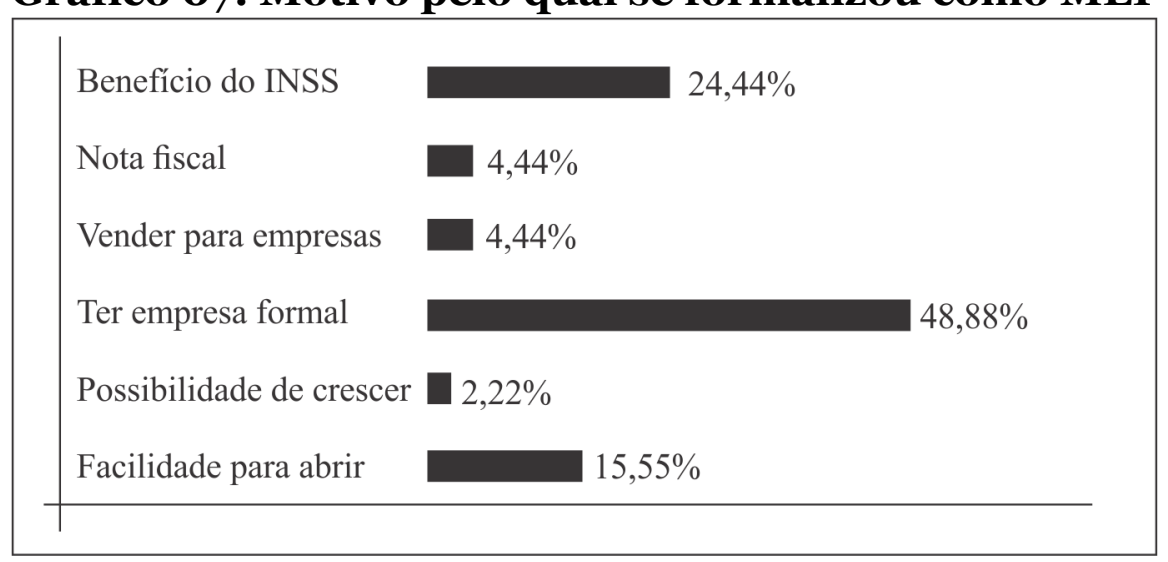

Fonte: elaborado pela autora.

Conforme já foi referido, uma das formas de precarização do trabalho se dá pela substituição do vínculo formal pelo trabalho autônomo. Neste sentido, os dados e entrevistas realizadas indicam a instabilidade no que se refere à manutenção do emprego assalariado e a formalização como um caminho para a segurança. São trabalhadoras que 


\section{A política pública do Microempreendedor Individual como instrumento de precarização do trabalho feminino}

já atuaram com carteira assinada, mas passaram a atuar como autônomas.

Eu sempre trabalhei no comércio, desde jovem. Comecei a trabalhar antes dos 20 anos. Trabalhei em muitos lugares. No último, já estava há cinco anos e tinha sido promovida de vendedora à caixa.[...] logo que saí do emprego, fiz um curso de manicure, fiz um registro como MEI e comecei a trabalhar como manicure.[...]Quem sabe um dia eu volte a trabalhar fora, mas, por enquanto, o MEI está bom.(Mulher de 39 anos, com ensino médio completo. Atua como manicure).

Eu fiz o MEI para trabalhar para uma empresa. Trabalhei lá como funcionária por cinco anos. É uma empresa que trabalha para eventos, então, tem épocas do ano que tem mais trabalho ou que tem menos. Nunca é igual. Aí, eles me fizeram essa proposta de me demitir e eu fazer o registro como MEI para trabalhar contratada, só quando tem serviço. Eu preferia antes, porque tinha carteira assinada, tinha férias, tinha tudo. Agora não tenho mais. (Mulher de 29 anos, com ensino fundamental completo. Trabalha com serviços gerais).

As entrevistas revelam, ainda que a política pública criada com o objetivo de proporcionar a formalização de trabalhadores que antes atuavam de maneira informal, pode ser usada por algumas empresas para substituir contratos de trabalho por relações de terceirização e prestação de serviços, uma das formas de precarização do trabalho. Além disso, observa-se uma tendência à banalização da precarização do trabalho e da vulnerabilidade, inclusive pelas próprias trabalhadoras que buscam na formalização como MEI uma possível segurança.

Eu sempre trabalhei como vendedora, vendendo de porta em porta. [...]Trabalho assim já faz 20 anos, mas só há dois é que fiz o MEI. Antes não tinha nada. Trabalhei 18 anos sem direito nenhum, sem pagar para me aposentar, sem nada. É uma pena, são 18 anos que perdi. Depois que fiz o MEI melhorou porque, agora, pelo menos sei que vou me aposentar. Também teve uma vez que fiquei doente e tive que ficar um tempo sem trabalhar, aí pedi o auxílio doença e recebi. Se não tivesse o MEI não ia receber nada. (Mulher, 42 anos, com ensino médio completo. Vendedora ambulante de artigos de vestuário).

Eu comecei no ano passado, quando estava trabalhando "frio" e eu via, principalmente, a questão da segurança, porque como eu ando de moto, sempre tive medo de sofrer um acidente, então, precisava de um suporte. Se acontecesse um acidente eu ia levar muito tempo para conseguir alguma coisa na justiça, requerer vínculo com a empresa e tudo mais. Eu já tinha trabalhado nessa empresa antes. Aí saí, fui trabalhar em outro lugar, depois voltei. Quando voltei, fiquei quase um 
ano trabalhando "frio", sem carteira assinada, sem contrato, sem nada. [...]Mas eu tinha medo de ficar assim, sem ter direito a nada, então, meu irmão que já tinha MEI fez um prá mim. (Mulher de 32 anos, com ensino superior completo, atua nos ramos da comunicação e da gastronomia).

Outra forma comum de precarização das relações de trabalho se manifesta na contratação temporária ou para tarefas específicas, o trabalho em tempo parcial e o trabalho intermitente. O que também está presente nas falas das entrevistadas.

Trabalhava esporadicamente, quando eles tinham alguma demanda maior, fazia alguns projetos especiais e tal, mas não era um trabalho que eu tivesse um horário fixo, que eu tivesse tarefas ou coisas definidas, era eventualmente, conforme a empresa precisava de mim. [...]Foi quando fiz um curso na área da gastronomia e comecei a fazer outras coisas para ter mais renda, então, além de trabalhar para esta empresa, eventualmente, faço massa caseira, bolachas, bolos...assim não fico dependendo só de lá, já que não é nada certo. (Mulher de 32 anos, com ensino superior completo, atua nos ramos da comunicação e da gastronomia).

Quando tem trabalho eles me chamam e eu vou, mas não é uma coisa certa. Às vezes tem, às vezes não. Assim, eu nunca sei ao certo quando vou ter trabalho ou não. Eu até sei as épocas do ano que eles têm mais serviço e que vão me chamar, mesmo assim, não é certo, né. Aí tem mês que ganho um salário, até dois, tem mês que não ganho nada. Então, estou procurando um serviço com carteira de novo. Depois que arrumar um serviço, se der para continuar trabalhando para eles assim, vai ser bom, se não der, paciência.(Mulher de 29 anos, com ensino fundamental completo. Trabalha com serviços gerais).

De acordo com as regras da política pública, cada microempreendedor individual pode ter até um funcionário com carteira assinada. Assim, seja pela necessidade de mais mão de obra, seja pela dificuldade em cobrir os custos da contratação de um funcionário, algumas MEIs acabam reproduzindo a lógica da terceirização e, consequentemente, da precarização com outras trabalhadoras.

Direto na produção, trabalhamos eu e minha auxiliar, que também é MEI. Fora isso, tenho cinco costureiras terceirizadas. Elas trabalham em casa, de acordo com a demanda. Então, eu aviso elas o que vai ter e elas já se programam. Elas conseguem trabalhar em casa, sempre têm trabalho e para mim fica bom porque se eu tivesse que contratar cinco ou seis funcionárias não ia conseguir pagar, além disso, como MEI só poderia contratar uma com carteira. Então, preciso de mais gente para 


\section{A política pública do Microempreendedor Individual como instrumento de precarização do trabalho feminino}

trabalhar, mas não tenho como contratar com carteira. Assim, terceirizando, fica bom. (Mulher de 25 anos, com ensino superior completo, proprietária de uma indústria de roupas).

Além dos aspectos já mencionados que se referem à insegurança no trabalho da mulher que atua como microempreendedora individual, outro ponto importante é a questão da dupla jornada e da sobrecarga das mulheres. Um problema que vem disfarçado de benefício no discurso que atribui positividade ao empreendedorismo feminino, como forma das mulheres se inserirem no mercado de trabalho, sem se afastarem do trabalho doméstico, mas que, na prática, se constitui em menos tempo dedicado ao trabalho remunerado e, consequentemente, menor renda. Além disso, nesta lógica, as mulheres continuam sendo as maiores responsáveis pelo trabalho doméstico não remunerado.

[...] tive que sair do meu emprego para ficar em casa cuidando da minha mãe. Normalmente, atendo em casa, mesmo, para não precisar sair porque se não tem ninguém para ficar com a minha mãe é difícil. Só que, por isso, também ganho menos do que poderia. Hoje, a minha renda fica entre $\mathrm{R} \$ 400,00$ e $\mathrm{R} \$ 500,00$. Não ajuda muito. [...] o MEI foi uma forma de eu poder continuar trabalhando, ganhando meu dinheiro, mesmo que seja pouco, e cuidando da minha mãe. Também consigo passar mais tempo com a minha filha e tenho mais tempo para cuidar da casa. [...] Eu que faço meu horário e posso dividir o tempo entre o trabalho, a casa, minha mãe, minha filha. Então, mesmo ganhando pouco, acho que está bom. (Mulher de 39 anos, com ensino médio completo. Atua como manicure).

Às vezes eu canso de trabalhar assim, porque é cansativo. Por um lado é bom porque eu faço o meu horário, posso cuidar da casa, de tudo e trabalhar. Mas vender, assim, na rua, às vezes é cansativo. No verão é muito ruim, mesmo assim tenho que ir, né, se não for, não vendo. As pessoas que me conhecem até vêm na minha casa, ou me ligam quando querem alguma coisa, mas a maioria das vezes sou eu que vou. (Mulher, 42 anos, com ensino médio completo. Vendedora ambulante de artigos de vestuário).

Desta forma, fica evidente que o trabalho em domicílio é mais uma das faces da precarização do trabalho feminino possibilitada pela política pública do microempreendedor individual.

Os depoimentos tomados nas entrevistas indicam que tanto as motivações para a formalização como MEI, quanto os significados que os trabalhadores atribuem à política pública, bem como as repercussões da formalização, no que se refere à inserção no mercado de trabalho, 
passam por diferentes relações e condicionamentos. Neste ponto, emerge uma contradição entre os objetivos com os quais a política pública foi criada e como ela é ressignificada, tanto por parte das próprias MEIs, quanto das demais empresas, trabalhadores, colegas e familiares com os quais elas estabelecem algum tipo de relação.

\section{Considerações finais}

Diante do que foi exposto, observa-se que a construção de significados para a Lei 128 de 19 de dezembro de 2008 está marcada por contradições e conflitos, presentes desde sempre no debate e na construção da política pública. A partir de uma concepção que a afirma a positividade do empreendedorismo, inclusive apresentando este caminho como uma solução às dinâmicas de desestruturação do mercado de trabalho no contexto das reformas neoliberais o Estado se afasta das responsabilidades quanto à criação de empregos e de proteção ao trabalho, transferindo essas responsabilidades para os indivíduos. Essa perspectiva aposta que, mesmo em condições adversas e situados em contextos históricos marcados por dinâmicas de exclusão social, de discriminação e de limitação de possibilidades, possam construir suas próprias histórias a partir de habilidades e competências desenvolvidas a partir de suas próprias forças.

No entanto, o que se percebe é a instrumentalização da política pública como mecanismo de precarização do trabalho, sobretudo das mulheres que, historicamente foram inseridas no mercado em condições diversas dos homens. Assim, a Lei do Microempreendedor Individual se constitui em uma ferramenta de manutenção das desigualdades de gênero, aumentando a exploração da força de trabalho feminina, tanto no trabalho produtivo, quanto no trabalho reprodutivo, ao mesmo tempo em que se suprimem os direitos trabalhistas básicos, como o emprego protegido, Fundo de Garantia por Tempo de Serviço e Seguro Desemprego.

É importante notar que as políticas públicas não são normativas, elas criam possibilidades, mas são os agentes, nas suas práticas cotidianas que as ressignificam e criam a realidade concreta. Neste caso, embora a Lei do Microempreendedor Individual tenha sido criada com o objetivo de proporcionar inclusão produtiva para trabalhadores informais, ela acaba se transformando em um instrumento de 


\section{A política pública do Microempreendedor Individual como instrumento de precarização do trabalho feminino}

exploração, precarização e supressão de direitos, potencializando os efeitos danosos da divisão sexual do trabalho.

\section{Referências}

ANTUNES, Ricardo. A nova morfologia do trabalho no Brasil: Reestruturação e precariedade. Rio de Janeiro, Revista da Praia Vermelha (Estudos de Política e Teoria Social) vol. 20/1, jun/ 2010.

BRASIL. Lei complementar n. 128 de 19 de dezembro de 2008. Disponível em http://www.planalto.gov.br

- Portal do Empreendedor, 2019, Disponível em http:// www.portaldoempreendedor.gov.br/

BRUSCHINI, C.; LOMBARDI, M. R. A Bipolaridade do trabalho feminino no Brasil contemporâneo. Cadernos de Pesquisa, n.110, p.67-104, jul. 2000.

BRUSCHINI, Maria C. A. Trabalho e gênero no Brasil nos últimos dez anos. São Paulo, Cadernos de Pesquisa, v. 37, n. 132, p. 537-572, set./dez. 2007

COLBARI, Antônia de L. A retórica do empreendedorismo e a formação para o trabalho na sociedade brasileira. In: SINAIS - Revista Eletrônica Ciências Sociais. Vitória: CCHN, UFES, Edição Especial de Lançamento, n.01, v.1, Abril. 2007. pp.75-111.

ENGELS, Friederich. A situação da classe trabalhadora na Inglaterra. São Paulo : Global, 1985.

GEM, Global Entrepreneurship Monitor. Empreendedorismo no Brasil : $2016 \backslash$ Coordenação de Simara Maria de Souza Silveira Greco; diversos autores. Curitiba: IBQP, 2017.

HARVEY, David. A Condição Pós-moderna. São Paulo: Edições Loyola, 2014.

HIRATA, Helena. Globalização, Trabalho e Gênero. Revista de Políticas Públicas, v. 09, n. ${ }^{0}$ 01, p. $111-128$. Jul/dez 2005. 
. A Precarização e a Divisão Internacional e Sexual do Trabalho. Sociologias, Porto Alegre, ano 11, $\mathrm{n}^{0}$ 21, jan./jun. 2009

IBGE. Mercado de trabalho reflete desigualdades de gênero. Agência I B G E Notícias, 2019 . Dis ponível e m https:// agenciadenoticias.ibge.gov.br/agencia-noticias/2012-agencia-denoticias/noticias/25223-mercado-de-trabalho-reflete-desigualdades-degenero

KERGOAT, Daniele. Dinâmica e consubstancialidade das relações sociais. Novos estud. - CEBRAP [online]. 2010, n.86, pp.93-103.

MANTOVANI, Emanuele. Microempreendedorismo Individual e Redes de Sociabilidade: uma análise da construção social do Microempreendedor Individual em Santa Cruz do Sul (RS). Dissertação. Programa de Pós-Graduação em Desenvolvimento Regional, Unisc. Santa Cruz do Sul, 2018.

NASCIMENTO, Sara D. Precarização do trabalho feminino: a realidade das mulheres no mundo do trabalho. Londrina, Anais do III Simpósio Gênero e Políticas Públicas.

NOGUEIRA, Claudia Mazzei. A feminização no mundo do trabalho: entre a emancipação e a precarização. Campinas/SP: Autores Associados, 2004.

POCHMANN, Márcio. O emprego na globalização. São Paulo: Boitempo Editorial. 2001.

SILVA, Luiz Antônio M. da. Da informalidade à empregabilidade (reorganizando a dominação no mundo do trabalho). Caderno $\mathrm{CRH}$, Salvador, n. 37, p. 81-109, jul./dez. 2002. 


\section{La Política Pública del Microempresario Individual como instrumento para la precarización del trabajo de las mujeres}

RESUMEN: La figura jurídica del Microempresario Individual fue creada en 2009 con el objetivo de reducir la informalidad y la inseguridad laboral, además de asegurar la inserción en el mercado de los trabajadores desempleados. Sin embargo, por su naturaleza, el trabajo como microempresario individual acaba representando una forma de relaciones laborales precarias, especialmente para las mujeres. Este artículo pretende analizar cómo la formalización como MEI, desde la institución de esta política pública, repercute en la precarización del trabajo femenino. Para ello se aplicaron formularios y se realizaron entrevistas semiestructuradas con mujeres que actúan como IME para identificar cómo las políticas públicas se convierten en un mecanismo y magnificación de la explotación del trabajo de las mujeres y de las desigualdades que resultan de la división sexual del trabajo.

Palabras ClaVE: Emprendimiento; Mercado laboral; Políticas públicas; División sexual del trabajo.

Emanuele MANTOVANI

Jornalista (UNISC), mestra em Desenvolvimento Regional - PPGDR (UNISC). Doutoranda no Programa de Pós-Graduação em Desenvolvimento Regional - PPGDR (UNISC).

Recebido em: 21/01/202O

Aprovado em: 09/11/2020 